\title{
Household environmental problems in developing countries
}

\author{
G. P. Shivashankara ${ }^{1} \&$ Siddegowda $^{2}$ \\ ${ }^{I}$ P.E.S. College of Engineering, Karnataka, India \\ ${ }^{2}$ S.J.C. Institute of Technology, Karnataka, India
}

\begin{abstract}
This paper explores household environmental problems in developing countries like India. Population density poses a major threat to household environmental conditions. To study the association between income and variables of household environment and health in the slums of Bangalore metropolitan city, a number of variables were considered. Data was collected with the help of a questionnaire from 4,560 households selected from 120 slums in the city. Water samples were collected from open containers used by slum dwellers and analyzed for quality parameters. Chi-square analysis indicates that income and environment conditions are significant at $1 \%$ level. The study shows that lack of basic amenities and poor living conditions increase pollutants around low-income households. The study found average incidence of dysentery compared to respiratory diseases, jaundice and malaria. The main reasons for higher incidence of dysentery are unsatisfactory water quality, storage of drinking water in open containers, disposal of fecal matter and lack of toilet facilities. Regression analysis shows positive correlation between diseases and other variables. Multiple regression models show that municipal collection of fecal matter and storage of water in open containers are significant variables. Further, the coefficient of determination, $R^{2}$, shows $92.9 \%$ variation in dysentery as shown by independent variables. The most severe household environmental problems and health effects are faced by the poor, i.e., low-income households. The study considers poverty to be the greatest polluter.
\end{abstract}

Keywords: slums, water, sanitation, diseases, health and statistical analysis. 


\section{Introduction}

The most-pressing environmental health problems today, in terms of disease, illness, disability and even death are associated with poverty in households and communities in developing countries like India. Slums, inadequate shelter, overcrowding, inadequate safe drinking water and sanitation, contaminated food, solid waste and indoor pollution are by far the greatest environmental threats to human health. These conditions are often compounded by poor nutrition and lack of education, which make people vulnerable and less able to cope with environmental threats. The low quality of life in slums is as much a result of unhygienic living conditions as is the lack of economic resource. Squalor accompanied by outbreak of diseases, high mortality and general ill-health make slum dwellers less productive. Many of the interventions particularly in the domain of public health, rely on changes in behavior and improvement in the environment at the household level, because a large share of diseases is contracted in or around the home environment. For instance, even if the water supply is clean at the public tap, it gets contaminated if stored unhygienically.

Bangalore urban area has grown so much that its administration is illequipped to respond to explosive changes. Rapid growth has taken its toll and many of the negative effects of urbanization, like pollution, inadequate infrastructure and loss of open space are experienced by residents. In particular, this growth has had a major impact on the environment leading to environmental degradation and formation of slums. While Bangalore has relatively fewer slums compared to India's major cities, the numbers are relative. Approximately 15-20 percent of metro Bangalore's residents are slum dwellers, compared to over 30 percent in Kolkata and Mumbai (Siddegowda and Shivashankara [1]). As a result, there is a great threat to health and quality of environment. The main objective of this research is to study the household environmental problems and their impact on environment and health.

\section{Materials and methodology}

The study was carried out with the help of both primary and secondary data. The primary survey is mainly composed of observations and interview through questionnaire method. There were 12 main questions which included particulars of housing details (states of house, type of house, and proper ventilation), study of demographic characteristics-(family size, literacy rate, income), reasons for migration (finance problem, employment problems, future of children, extreme poverty, land problems, state of rural infrastructure, public utilities, natural disasters, government facilities, wage rate, literacy rate), household (sources of water supply, state of water supply, quality of water supply, amount of water supply, mode of water storage), utility services (status of road and sanitation), health (name the four most frequency reported disease of the family, name the four most important household environmental problems that should be improved) and medical facilities, market and recreation facilities, disposal of garbage and sullage (mode of storage of household waste inside the house, mode 
of disposal of household waste, garbage collections by the municipality, frequency of garbage collection), solid waste, drainage system (disposal of household wastewater, drainage around the house, type of drainage, water logging around the house, types of water logged) and latrine facility, and space index (living area, density and floor area). Since there are as many as 473 slums (declared as slums in 204) in Bangalore metropolitan city it was difficult to conduct socio-economic survey of all of them. Hence, for study purpose, the city was spatially stratified into three ecological zones-core, intermediary and periphery - on the basis of population density characteristics. Data was drawn with the help of a questionnaire from a survey of 4560 households selected from 42 slums from core, 43 from intermediary and 35 from periphery of the city (Table 1). The questionnaire used in the interview was developed with the help of questionnaires of similar studies conducted by the Stockholm Environment Institute (SEI, 1993, 1994 and 1995) and Aligarh Environment Study Project (AESP, 1994, 1995). It records all persons occupying a housing unit correctly, put their feet under one table or otherwise join together in an arrangement to provide, food, clothing, shelter and other basic residential necessities (Schei et al. [2] and Siddegowda and Shivashankara [3]). The spatial distribution of the sample slums is shown in Figure 1.

Table 1: Basic data from three ecological zones with respect to sample slums.

\begin{tabular}{||l|l|l|l|l|}
\hline Bangalore & Core & Intermediary & Periphery & Total \\
\hline \hline $\begin{array}{l}\text { Size of } \\
\text { sample } \\
\text { households }\end{array}$ & 928 & 1531 & 2101 & 4560 \\
\hline $\begin{array}{l}\text { Number of } \\
\text { sample slums }\end{array}$ & 42 & 43 & 35 & 120 \\
\hline
\end{tabular}

The lack of basic amenities like water supply, sanitation and solid-waste collection in slum areas will affect water sources. Only four slums were randomly selected in Bangalore Metropolitan city for study purpose for analysis of drinking water quality. Twelve stations were established for collection of water samples from open containers. This study examined the probable cause of pollution in drinking water and the quality of household drinking water (before and after use) was analyzed. During the study period (Feb, May, April 2007), drinking water samples were collected from four select stations in slums of core, intermediary and periphery areas of the city and analyzed for water-quality parameters as per standard methods [4]. 


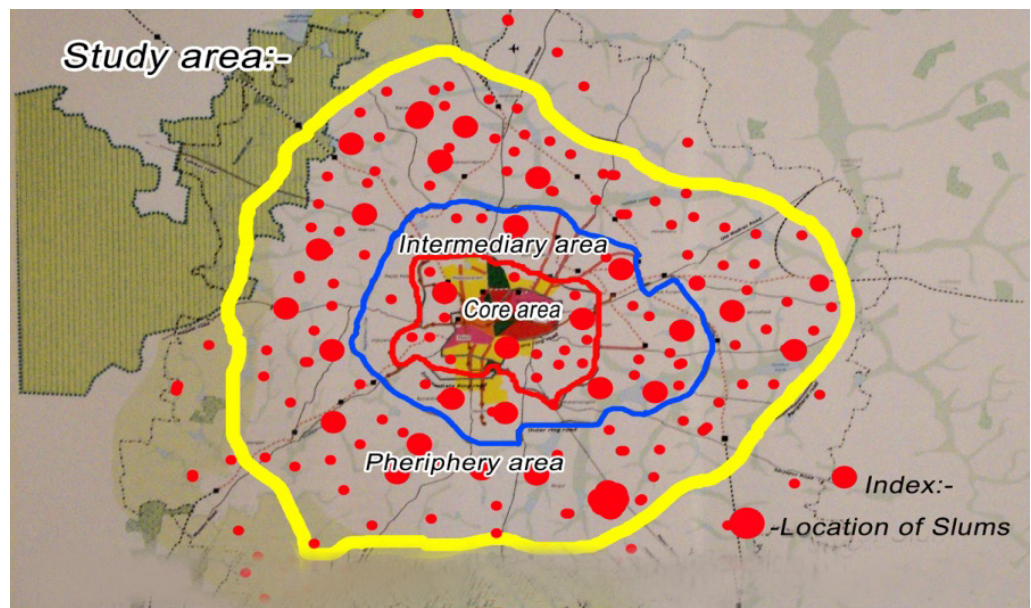

Figure 1: Location of sample slums in core, intermediary and periphery areas of Bangalore metropolitan city.

\section{Results and discussion}

\subsection{Distribution of sampled households according to income}

Household income is an important variable considered to examine social background. In the case of unorganized sector, assessing income is a difficult and ticklish issue as people here do not have regular income, and also do not keep track of their incomes. Yet this variable cannot be ignored. Income gives clues to economic status of households (Siddegowda and Shivashankara [1] and Schei et al. [2]). As illustrated in Table 2, 37.93\% of the total sampled households belong to low, $28.35 \%$ to medium, and $33.72 \%$ to high-income groups. The study establishes that majority of the slum dwellers belong to lowand medium-income groups in the city as the income derived from their jobs is less.

Table 2: Distribution of the sampled households according to income.

\begin{tabular}{|c|c|c|c|}
\hline $\begin{array}{c}\text { Income } \\
\text { Group }\end{array}$ & $\begin{array}{c}\text { Income } \\
\text { (Rupees per } \\
\text { month) }\end{array}$ & $\begin{array}{c}\text { No. of sampled } \\
\text { households }\end{array}$ & Percentage \\
\hline \hline Low & $1500-2999$ & 1730 & 37.93 \\
\hline Medium & $3000-4999$ & 1293 & 28.35 \\
\hline High & $5000-9000$ & 1537 & 33.72 \\
\hline & Total & $\mathbf{4 5 6 0}$ & $\mathbf{1 0 0 . 0 0}$ \\
\hline
\end{tabular}

Source: Field survey 2006. 


\subsection{Association between income and household environmental conditions}

In order to find association between income and variables of household environmental conditions such as the status of the house in the slums of Bangalore metropolitan city, a number of variables were used. Chi-square analysis was done. Table 3 shows that income and household environment conditions are significant at $1 \%$ level. Higher coefficients of values were observed for the variables. It has been observed that fuel used for cooking food (0.6304), water logging around the houses (0.6000), type of latrine used (0.5997), place of cooking food (0.5992), mode of storing of household waste $(0.5665)$, bathroom and toilet facility in the house $(0.5607)$, source of water supply (0.5607), quality of water supply (0.5607), type of drainage around the house $(0.5568)$, drainage around the house $(0.5417)$ are strong associates with income and household environmental conditions. Similar studies have examined income and household environmental problems and have established that poor living conditions in informal settlements have detrimental effect on health (Surjadi et al. [5], Graham et al. [6] and Kwasi Boadi [7]).

The present study shows wide disparities among different wealth groups regarding access to environmental health facilities and services. Household environmental problems are closely interrelated and affect mainly low-income households. Lack of access to facilities has created severe environmental and sanitation problems such as indiscriminate dumping of refuse and discharge of wastewater into the environment which pose major health hazards. Lack of basic amenities and poor living conditions increase pollutants around low-income households. This proves that poverty is the greatest polluter. The pollutants also migrate to non-slum areas through various media.

\subsection{Drinking water quality}

It was found during the survey that $82.48 \%$ of the low-income and $81.44 \%$ of medium-income households were getting water of unsatisfactory quality (Siddegowda and Shivashankara [1]). Samples of water stored in open containers contain large quantities of impurities and all the parameters did not meet with permissible limits of drinking water-quality standards (Table 4). The study shows that drinking water is not stored and used properly in the houses of slum dwellers. Lower-income households thus consume mostly polluted water. Results of previous studies agree with our findings which show that the quality of water deteriorates significantly after collection, i.e. contamination occurs in transport vessel or in the household domain in general. Improper cleaning of storage and transport containers has been described as a key source of contamination of drinking water (Maiti and Agrawal [8]).

\subsection{Relation between income, household environment and health}

About one-fifth of the total disease burden in developing countries can be associated with environmental risk factors. While the disease burden in poor countries is about twice that of richer countries that from environmental risk is 
Table 3: Association between income and household environmental conditions.

\begin{tabular}{|c|c|c|c|}
\hline $\begin{array}{l}\text { Sl. } \\
\text { No. }\end{array}$ & Variables & $x^{2}$ & $\begin{array}{l}\text { Coefficient } \\
\text { of contiguity }\end{array}$ \\
\hline$\overline{11}$ & Status of the house & $68.17 *$ & 0.1213 \\
\hline 2 & House type & $267.81^{*}$ & 0.2365 \\
\hline 3 & Floor area of the house & $267.308^{*}$ & 0.2353 \\
\hline 4 & Total number of rooms in the house & $547.407 *$ & 0.3273 \\
\hline 5 & Average area of the rooms & $345.903 *$ & 0.2655 \\
\hline 6 & $\begin{array}{l}\text { Floor space per person in sleeping } \\
\text { rooms }\end{array}$ & $1964.88^{*}$ & 0.5487 \\
\hline 7 & Ventilation condition in the house & $685.72 *$ & 0.3615 \\
\hline 8 & $\begin{array}{c}\text { Bathroom and toilet facility in the } \\
\text { house }\end{array}$ & $2091.49^{*}$ & 0.5607 \\
\hline 9 & Type of latrine used & $2561.58^{*}$ & 0.5997 \\
\hline 10 & $\begin{array}{l}\text { The mode of disposal of fecal } \\
\text { matter from manual latrines }\end{array}$ & $66.27 *$ & 0.1196 \\
\hline 11 & Source of water supply & $2091.49^{*}$ & 0.5607 \\
\hline 12 & State of water supply & $125.931^{*}$ & 0.1639 \\
\hline 13 & Quality of water supply & $2091 *$ & 0.5607 \\
\hline 14 & Amount of water supply & $364.78^{*}$ & 0.2721 \\
\hline 15 & Mode of water storage in the house & $185.55^{*}$ & 0.1975 \\
\hline 16 & Drainage around the house & $1894^{*}$ & 0.5417 \\
\hline 17 & Type of drainage around the house & $2049 *$ & 0.5568 \\
\hline 18 & Water logging around the house & $2565^{*}$ & 0.6000 \\
\hline 19 & Mode of storage of household waste & $2155^{*}$ & 0.5665 \\
\hline 20 & $\begin{array}{l}\text { Mode of disposal of household } \\
\text { waste }\end{array}$ & $1271.71^{*}$ & 0.4669 \\
\hline 21 & Garbage collection & $45.18^{*}$ & 0.0990 \\
\hline 22 & Frequency of garbage collection & $191 *$ & 0.2005 \\
\hline 23 & $\begin{array}{l}\text { Distribution of fly doors and } \\
\text { windows }\end{array}$ & $408.25^{*}$ & 0.2866 \\
\hline 24 & Place of cooking food in slums & $2555^{*}$ & 0.5992 \\
\hline 25 & Fuel used for cooking food & $3008 *$ & 0.6304 \\
\hline 26 & Indoor smoking & $1294 *$ & 0.4701 \\
\hline
\end{tabular}

Source: Field survey 2006.

${ }^{*}$ Chi-square is significant at $1 \%$ level. 
Table 4: Water-quality parameters, samples collected from open containers in the sampled households.

\begin{tabular}{|c|c|c|c|c|c|c|c|c|c|c|}
\hline Location & $\begin{array}{c}\begin{array}{c}\text { Sample } \\
\text { points }\end{array} \\
\text {. }\end{array}$ & $\mathrm{pH}$ & EC & TH & $\mathrm{Fe}$ & $\mathbf{F}$ & $\mathrm{Cl}^{-}$ & $\mathrm{SO}_{4}^{-}$ & $\mathrm{NO}_{3}^{-}$ & E-Coli \\
\hline \multirow{3}{*}{$\begin{array}{l}\text { Jakkarayanakere, } \\
\text { Behind Church } \\
\text { (Gandhi Nagar) }\end{array}$} & J1 & 7.57 & 1810 & 319 & 0.31 & 0.66 & 330 & 194 & 66 & 10 \\
\hline & $\mathrm{J} 2$ & 7.69 & 1790 & 330 & 0.33 & 0.71 & 315 & 102 & 64 & 12 \\
\hline & J3 & 8.00 & 1850 & 311 & 0.32 & 0.72 & 300 & 189 & 62 & 11 \\
\hline \multirow{3}{*}{$\begin{array}{l}\text { Bapuji Nagar } \\
\text { (Binnypet) }\end{array}$} & J1 & 7.90 & 1650 & 300 & 0.29 & 0.67 & 299 & 120 & 59 & 13 \\
\hline & $\mathrm{J} 2$ & 7.77 & 1750 & 295 & 0.21 & 0.71 & 285 & 134 & 63 & 10 \\
\hline & J3 & 7.69 & 1900 & 319 & 0.19 & 0.75 & 289 & 176 & 61 & 12 \\
\hline \multirow{3}{*}{$\begin{array}{l}\text { Intermediary } \\
\text { Gandhi Nagar } \\
\text { (Malleswaram) }\end{array}$} & B1 & 7.85 & 1650 & 312 & 0.27 & 0.69 & 291 & 169 & 60 & 11 \\
\hline & B2 & 7.91 & 1450 & 319 & 0.26 & 0.81 & 288 & 173 & 65 & 11 \\
\hline & B3 & 7.90 & 1800 & 315 & 0.26 & 0.31 & 295 & 182 & 63 & 10 \\
\hline Periphery & S1 & 7.60 & 1900 & 299 & 0.31 & 0.4 & 310 & 201 & 61 & 14 \\
\hline \multirow{2}{*}{$\begin{array}{l}\text { Nayendanahalli } \\
\text { (Uttarahalli) }\end{array}$} & S2 & 7.79 & 1850 & 295 & 0.32 & 0.3 & 312 & 194 & 62 & 3 \\
\hline & S3 & 8.10 & 1750 & 285 & 0.33 & 0.35 & 320 & 191 & 64 & 9 \\
\hline
\end{tabular}

All units are in $\mathrm{mg} / \mathrm{L}$ except $\mathrm{pH}$ (dimensionless), and $\mathrm{TH}=$ Total hardness $\left(\right.$ as $\left.\mathrm{CaCO}_{3}\right)$, $\mathrm{EC}\left(\mu \mathrm{S} . \mathrm{cm}^{-1}\right) ; E$. coli is represented in number of colonies per 100Ml.

ten times greater than in developing countries. Statistical analysis was carried out to study the relationship among income, environment and health in all zones of Bangalore's slums. Statistical analysis was done for pooled data of core, intermediary and periphery of the urban area (Table 5). Data shows mean and standard deviation for dysentery, jaundice, malaria and respiratory diseases in all the slum zones of the city; estimates stemming from different risk contexts is the focus in this analysis. One can notice that the standard deviation is much larger than the mean for all risk categories, reflecting the large span in the estimates covered and that the median value is much lower than that in each case reflecting the long right-hand tails of the distributions.

Table 5 shows the average incidence of diseases like dysentery, jaundice, malaria and respiratory diseases along their variables of pooled data (overall) in the slums of Bangalore city. The average incidence of dysentery was more compared to respiratory diseases, jaundice and malaria. The major reasons for 
higher incidence of dysentery are unsatisfactory water quality, storage of drinking water in the open container, disposal of fecal matter and no latrine facilities. Similarly, outdoor smoke coming into the house, no outlet for indoor smoke, no proper ventilation, place of cooking and wood as main cooking fuel are the main causes of respiratory diseases. The study establishes that dysentery and respiratory diseases are common in the slum areas of all zones of the city.

\subsection{Multiple regression analysis}

Multiple regression models were used for pooled data to ascertain contributing variables to diseases in the slums of Bangalore city (Table 6). It is found that municipal collection of fecal matter and storage of water in open containers are significant variables. The coefficient of determination, $R^{2}$, shows that there is $92.9 \%$ variation in dysentery as explained by independent variables, whereas in the case of jaundice, sources of water (storage of water in open containers) contribute more significantly. However, other variables like unsatisfactory water quantity are found not significant. Further, the value of $R^{2}$ is found to be $85.6 \%$. In the case of malaria, $\left(R^{2}=87.6 \%\right)$, all variables in the model contribute significantly. However, other variables like open drainage, no use of fly doors and windows in the house were found not significant. With respect to respiratory diseases $\left(R^{2}=96.7 \%\right)$, except for space per person for sleeping, which is less than $10 \mathrm{sq} \mathrm{ft}$, the place for cooking meal which is generally verandah /multipurpose hall and cigarette/bidi smoking inside the house, which are variable significantly, contribute to these diseases.

The study shows relationship between access to quality drinking water and sanitation vis-à-vis the incidence of diarrhea as demonstrated by other studies (Dittrich [9] and Osumanu [10]). All these studies have emphasized the importance of environmental factors in determining the incidence of diarrhea. The complex factors contributing to malaria risk in slums of Bangalore city are not fully understood but statistical analysis shows that rapidly accumulating urban poor (slum dwellers) are at far higher risk (Roberts [11] and Ezzati and Kammen [12]). Respiratory infections are transmitted by airborne particles, droplets or by physical contact. Indoor crowding, poor ventilation and a lack of sunlight increase the danger of cross-infection. Exposure to air-borne irritants such as smoke from cooking fire can predispose the body to respiratory disease and increase the likelihood of secondary infections (Siddegowda and Shivashankara [3]). Similar studies have examined the household environmental problems which are closely inter-related and mainly affect low-income households (Surjadi et al. [5], Graham et al. [6], Maiti and Agrawal [8], Ezzati, and Kammen [12], Kirkr et al. [13]). Poor sanitation results in high incidence of infectious diseases including malaria and diarrhea.

The study shows that the slum dwellers lack basic amenities because of poor economic conditions. This leads to common diseases like dysentery and respiratory infections. The main factors contributing to dysentery are no latrines, improper methods of disposal of fecal matter, and storage of water in open 
Table 5: $\quad$ Mean and standard deviation for dysentery, jaundice, malaria and respiratory diseases.

\begin{tabular}{|c|c|c|}
\hline Variable & Mean & S.D \\
\hline Dysentery & 4.6037 & 7.09366 \\
\hline No latrines & 3.7893 & 6.99981 \\
\hline Municipal collection of fecal matter & 3.8428 & 5.63776 \\
\hline Disposal of fecal matter in garbage & 5.7542 & 7.34036 \\
\hline Unsatisfactory water quality & 4.5886 & 7.59736 \\
\hline Storage of water in open containers & 3.9114 & 7.04642 \\
\hline Jaundice & 3.1683 & 4.95253 \\
\hline Using water from sources & 2.3817 & 4.64420 \\
\hline Unsatisfactory water quantity & 4.8283 & 7.82267 \\
\hline Storage of water in open containers & 3.7283 & 7.16776 \\
\hline Malaria & 3.7283 & 4.87622 \\
\hline Open drainage & 4.4083 & 6.29160 \\
\hline Water-logging problem & 4.5817 & 7.00131 \\
\hline Both water- and rain-water logging & 2.4450 & 2.85667 \\
\hline Presence of household -pests & 2.6983 & 3.52866 \\
\hline No use of fly doors and windows in the house & 5.2567 & 7.34011 \\
\hline No use of preventive measures for mosquitoes & 3.3050 & 5.03364 \\
\hline Respiratory disease & 3.5133 & 5.99470 \\
\hline Space per person in sleeping (less than $10 \mathrm{sq} \mathrm{ft}$ ) & 2.0733 & 4.27142 \\
\hline No proper ventilation in the house & 3.3667 & 6.65151 \\
\hline $\begin{array}{c}\text { Place of cooking meal (verandah/multipurpose hall) } \\
\text { Main cooking fuel used }\end{array}$ & 2.9750 & 5.80407 \\
\hline Outdoor smoke coming into the house & 2.8383 & 5.43735 \\
\hline Cigarette/bidi smoking inside the house & 4.0317 & 7.05149 \\
\hline \multirow[t]{2}{*}{ No outlet for indoor smoke } & 4.1983 & 7.43939 \\
\hline & 3.7883 & 7.40326 \\
\hline
\end{tabular}

Source: Computed from survey data 2006.

containers; the main factor contributing to respiratory infections is improper ventilation in the house, where predominantly the cooking fuel used is wood. The most severe household environmental problems and health effects are faced by the poor, i.e. low-income households. It is evident that the major obstacle to achieving sound environmental health in the slums of Bangalore metropolitan city is poverty. 
Table 6: Multiple regression models explaining the contribution of variables to various diseases (Pooled data).

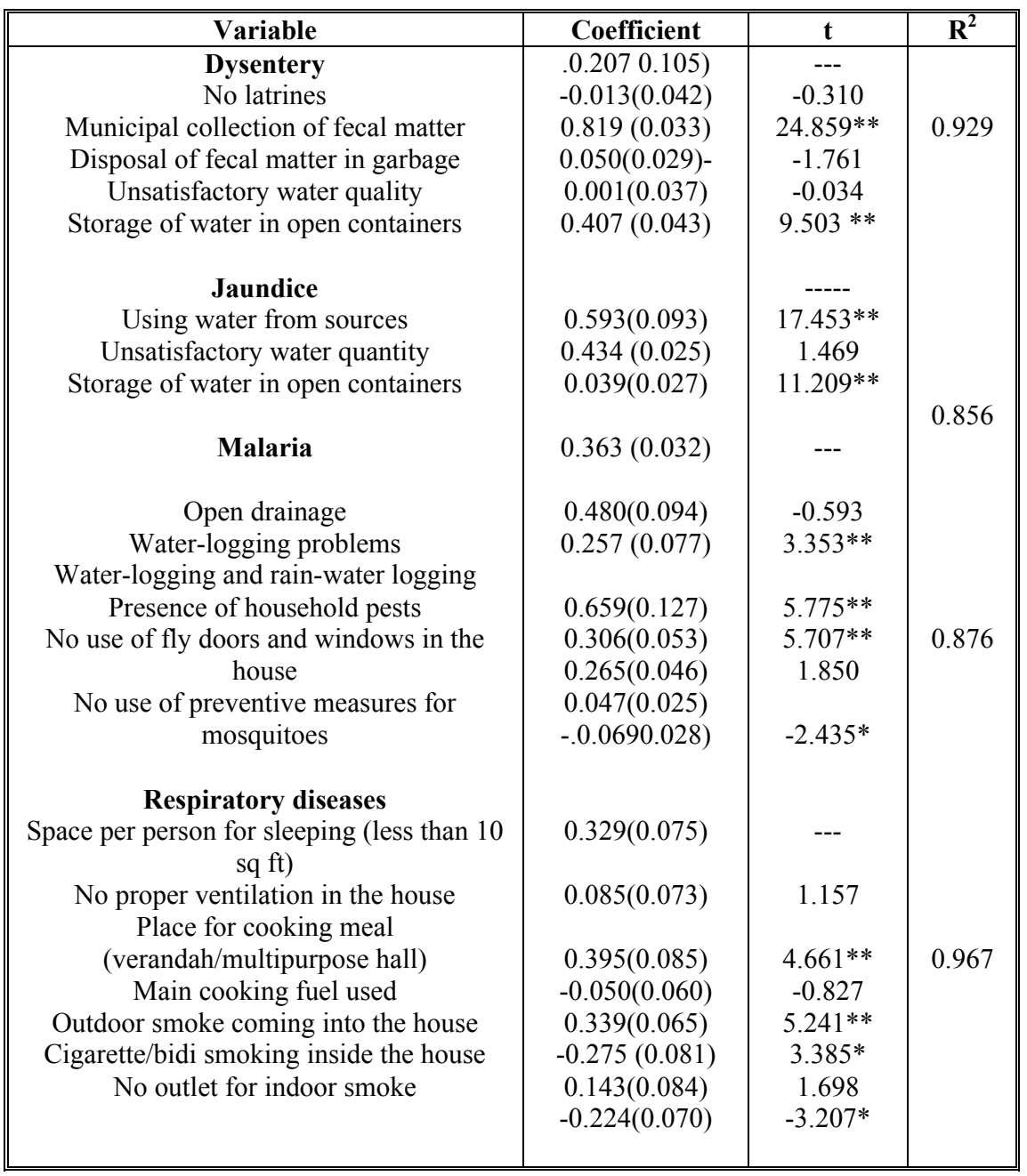

Source: computed from survey data 2006.

\section{Conclusions}

This study shows that the quality of life of the slum dwellers is very poor because of inadequacy of income derived from job and dependency. Household environmental problems are closely inter-related and affect mainly low-income households. Lack of access to facilities has created severe environmental and sanitation problems such as indiscriminate dumping of refuse and discharge of sewage and wastewater into the environment which pose major health hazards 
poor sanitation results in high incidence of infectious diseases including malaria, diarrhea and respiratory diseases. The study shows that slum dwellers suffer from lack of basic amenities. Multiple regression analysis shows that there is a close relationship between income, household environment and health. In the low-income households, the household environmental conditions are poor with a risk of environment-related problems like diarrhea/dysentery, malaria, jaundice and respiratory infections. Poverty-related social risk factors and environmental deprivation all combine to contribute to ill-health. Indeed, the role of poverty seems to be in large part a reflection of difficulties which poorer households face in achieving adequate environmental conditions. Poverty is the greatest polluter. This is our basic hypothesis.

\section{References}

[1] Siddegowda, and Shivashankara, G.P. "Rural to urban migration and household environmental problems in slums of Bangalore Metropolitan city", Visvesvaraya Technological University, Belgaum, Karnataka, India, 2011.

[2] Schei, M. A., O. Jens, J. O. Hessen, K. R. Smith, N. Bruce, J. Mccrackenc, and V. Lopez, "Childhood Asthma and Indoor Wood Smoke from Cooking in Guatemala", Journal of Exposure Analysis and Environmental Epidemiology, Vol. 14, pp. 110-117, 2004.

[3] Siddegowda, and Shivashankara, G.P. Urbanization, Slums and Indoor Air Pollution in Developing Countries. International Journal of Environmental, Cultural, Economic \& Social Sustainability, Vol. 4, Issue 6, pp. 33-40, 2009.

[4] APHA, AWWA and WPCF, "Standard Methods for the Examination of Water and Wastewater", American Public Health Association, New York, 2005.

[5] Charles Surjadi., Lesmana Padmasutra and Dotti Wahy Uningsih, "Household Environmental Problems in Jakarta", Stockholm Environment Institute, 1994.

[6] Graham J.P., Corella Barnd V., Avita Diaz R \& Gurina P. "The in-Home Environment and Household Health, A Cross-Sectional Study of Informal Urban Settlements in Northern Mexico", International Journal of Environment Research Pubic Health, pp. 394-402, 2005.

[7] Kwasi Boadi, "Environment and Health in the Accra Metropolitan Area, Ghana, Jyvashkyla", Studies in Biological and Environmental Science, University of Jyvaskyla, 2004.

[8] Maiti S \&. Agrawal, P. K, "Environmental Degradation in the Context of Growing Urbanization: A Focus on the Metropolitan Cities of India", Journal of Hum Ecologies, 17(4) pp. 277-287, 2005.

[9] Christoph Dittrich, Bangalore: Globalization and Fragmentation in India high tech-capital. ASIEN, 103, pp. 45-58, 2007. (http://www.asienkunde.de /articles/A103_Dittrich.pdf) 
[10] Issaka Kanton Osumanu, "Household Environmental and Behavioral Determinants of Childhood Diarrhoea Morbidity in the Tamale Metropolitan Area (TMA), Ghana Geografisk Tidsskrift Danish Journal of Geography, 107(1) pp. 59-68, 2007.

[11] Roberts L "Keeping Water Clean in a Malawi Refugee Camp: A Randomized Intervention Trial", Bulletin of the world Health Organization 79 (4): pp. 280-287, 2001.

[12] Ezzati, M., and Kammen, D.M., "Quantifying the Effects of Exposure to Indoor Air Pollution from Biomass Combustion on Acute Respiratory Infections in Developing countries", Environment Health Perspect, 109: pp. 481-489, 2001

[13] Kirkr, Smith \& Majid Ezzati "How Environmental Health Risks Change with Development", Annu Rev Enusen Resomler 30: pp. 291-333, 2001. 